\title{
Smart mobile phone usage pattern by students of professional colleges and it's dependence: A comparative profile
}

\author{
Naidu RDR ${ }^{1 *}$, De $A^{2}$, Vijaya $\mathrm{K}^{3}$ \\ *Corresponding author: \\ ${ }^{1}$ Dr. R. D. Ramesh Naidu MD Student, Community \\ Medicine, NRI Institute of Medical Sciences, \\ Visakhapatnam, India. \\ Email: drrameshnaidu@gmail.com ORCID \\ ${ }^{2}$ Professor \& Head, Community Medicine, NRI Institute of \\ Medical Sciences, Visakhapatnam, India \\ ${ }^{3}$ Professor, Community Medicine, NRI Institute of \\ Medical Sciences, Visakhapatnam, India
}

\section{Information about the article:}

Received: Jan. 17, 2019

Accepted: Feb. 20, 2019

Published online: Dec. 27, 2019

\section{Publisher}

Nepal Health Research Society, Bahundhara -6, Gokarnesowor Municipality, Kathmandu, Nepal

eISSN 2382-5545, ISSN 2676-1343 (Print)

(c) The Author(s). 2019

Content licensing: CC BY 4.0

\section{ABSTRACT \\ Background \\ Mobile phones have become an indispensable part of modern human life. With the ever-increasing utilization of smart phones, several psychological \& behavioural problems have emerged. Excessive use of smart phones has also led to poor academic performance among students. Keeping all these points in mind, a study was conducted in professional colleges to obtain base line data. Objectives: To assess the usage pattern of smart mobile phone among students of professional colleges and to evaluate the mobile phone dependence in students of professional colleges.}

\section{Materials and methods}

In Visakhapatnam, a cross-sectional study was conducted among 100 Medical \& 100 Engineering students selected by random sampling technique. Data were collected using a pre-designed\& pre-tested questionnaire from October 2018 to November 2018. SAS-SV Scale was used to assess the mobile phone dependence. Collation of data was done using inferential statistical methods.

\section{Results}

The study population of Medical group consisted of 32\% males \& 68\% females; of these $45 \%$ were Day scholars \& $55 \%$ were residents of hostels. The study population of Engineering group consisted of $63 \%$ males\& $37 \%$ females; of these $76 \%$ were Day scholars \& $24 \%$ were residents of hostels. The majority of students in both the professional groups were of the age group of 19 years. While assessing mobile phone usage pattern, it was found that age of initiation of mobile phone use was above 15 years in $88.5 \%$ in both the groups. $75 \%$. of students in both the groups were using mobile phone between 1-6 hours a day. 45\% of students were using mobile phone at home while $55 \%$ were using while on move. While 32\% students had Addiction scale more than SAS-SV: cut off 31; factors like daily life Disturbance, withdrawal, cyber space-orientation relationship, overuse etc. 33\% students were in the range of being at risk group (SAS-SV: 20 to 30). Out of $19 \%$ Medical \& 32\% Engineering students who attended calls while driving, $26 \%$ \& $25 \%$ continued conversation while still driving in both the groups respectively.131students often woke up from their sleep to check whether they had a Notification or a Missed call or SMS $(\mathrm{P}=<0.01)$. False perception of mobile phone ringing was present among $12 \%$ of Medical and $14 \%$ of engineering students.

\section{Conclusion}

The study showed an increased dependence of mobile phone use among Medical \& Engineering students, which imparts a negative effect on physical and mental health \& also poor academic performance.

Key words

Smart mobile phone usage, dependence, professional colleges 